\title{
DESNACIONALIZAÇÃO E INTERNACIONALIZAÇÃO NA AGRICULTURA BRASILEIRA: IMPACTOS ESTRATÉGICOS NO CASO DO SETOR DE SEMENTES
}

João Luciano Bandeira ${ }^{1}$

Marlon Clóvis Medeiros ${ }^{2}$

Resumo: O trabalho faz uma discussão acerca da desnacionalização e internacionalização da agricultura brasileira, dando destaque para os fatores que levaram ao atual cenário de dependência para as corporações transnacionais. É dada ênfase no setor de sementes pelo caráter estratégico que passou a ter após o aprofundamento da financeirização na agricultura após inovações tecnológicas das últimas décadas.

Palavras-chave: Desnacionalização. Internacionalização. Setor de Sementes. Transgênicos. Royalties na Agricultura.

\section{DESNATIONALIZATION AND INTERNATIONALIZATION IN BRAZILIAN AGRICULTURE: STRATEGIC IMPACTS IN THE CASE OF THE SEED SECTOR}

Abstract: The paper discusses the denationalization and internationalization of Brazilian agriculture, highlighting the factors that led to the current situation of dependence on transnational corporations. Emphasis is placed on the seed sector because of the strategic nature it has had after the deepening of financialization in agriculture after technological innovations in recent decades.

Keywords: Denationalisation. Internationalization. Sector of Seeds. Transgenic. Royalties in Agriculture.

\section{DESNACIONALIZACIÓN E INTERNACIONALIZACIÓN EN LA AGRICULTURA BRASILEÑA: IMPACTOS ESTRATÉGICOS EN EL CASO DEL SECTOR DE SEMILLAS}

Resumen: El trabajo hace una discusión sobre la desnacionalización e internacionalización de la agricultura brasileña, destacando los factores que llevaron al actual escenario de dependencia para las corporaciones transnacionales. Se hace énfasis en el sector de semillas por el carácter estratégico que pasó a tener después de la profundización de la financierización en la agricultura después de las innovaciones tecnológicas de las últimas agriculture after technological innovations in recent decades.

Palabras clave: Desnacionalización. Internacionalización. Sector de Semillas. GM. Royalties en la Agricultura.

\footnotetext{
${ }^{1}$ Universidade Federal de Santa Catarina, Departamento de Geociências, Florianópolis, Brasil, País, joao.bandeira@ifpr.edu.br, https://orcid.org/0000-0001-7521-6832

2 Universidade Estadual do Oeste do Paraná, Departamento de Geografia, Francisco Beltrão, Brasil, marlonmedeiros@hotmail.com, https://orcid.org/0000-0002-4648-6662
} 


\section{Introdução}

O tema da desnacionalização e desindustrialização tem preocupado os pensadores comprometidos com o Brasil. Após o desenvolvimento da Nação no seio de uma industrialização tardia, baseada num amplo processo de substituição de importações, uma abertura econômica com pouca perícia para o tema e a entrada do País num sistema de leis internacionais de comércio que não necessariamente 0 beneficiava, fizeram com que setores chave na economia nacional se desnacionalizassem. Na sequência se aprofunda o processo de desindustrialização e os problemas decorrentes, como baixo crescimento econômico, desemprego, desequilíbrio entre o valor agregado das exportações e das importações e déficit na balança comercial.

No agro brasileiro, se viu uma desnacionalização sem precedentes no setor de insumos, ou setor a montante da agricultura. Empresas que forneciam químicos, equipamentos e máquinas se viram desamparadas em um cenário de economia em crise no final dos anos 1990 com problemas para exportar devido ao câmbio valorizado e a uma abertura econômica em cenário de grande fluidez do capital internacional. As empresas nacionais estiveram reféns ao não conseguirem o sucesso necessário após os investimentos feitos nos meandros do lançamento do plano Real, com concorrentes adentrando em seus mercados de forma bastante agressiva.

O setor de sementes se torna pertinente para observarmos o ocorrido, com base na importância que tem hoje. Este segmento à montante da agricultura foi desnacionalizado praticamente em plenitude, nas grandes culturas agrícolas nacionais. Este amplo processo de desnacionalização é mais grave quando analisamos sua dinâmica financeira, com um grande arcabouço de royalties que se criou na sequência, respondendo ao questionamento do porquê este setor foi tão visado por corporações que nem mesmo eram do segmento de sementes em sua origem.

Desta forma, procuramos contribuir para o entendimento e dimensionamento do processo de desindustrialização e desnacionalização no Brasil, discutindo e esboçando os desdobramentos deste processo na agricultura, enfatizando o setor de sementes. Nos preocupamos em responder ao questionamento acerca dos 
impactos provocados por essa desnacionalização, em que a produção de grãos trataremos com maior ênfase de milho e soja - se dá em grandes proporções no território nacional, sendo o Brasil uma referência mundial em sua produção, porém com altas taxas de royalties sendo pagas pelo setor para a obtenção e utilização das tecnologias utilizadas na produção. Assim reverte-se juntamente com os lucros obtidos em território nacional por parte das transnacionais, boa parte da renda obtida com a atividade para o estrangeiro.

$\mathrm{O}$ trabalho se apresenta em duas partes. Na primeira parte discutimos $\mathrm{O}$ processo de desnacionalização da economia brasileira, dando maior destaque para o setor de insumos. Apresentamos um debate sobre a desnacionalização que ocorreu com a compra de empresas brasileiras por grandes grupos internacionais.

$\mathrm{Na}$ segunda parte, aprofundamos o debate no setor de sementes, que se converteu em um setor dinâmico, ao qual preferimos chamar em diversas ocasiões como setor genético vegetal. Este setor, em sua dinâmica de inovação acelerada dos anos 2000 deu ferramentas eficientes para o sistema financeiro drenar renda em territórios espalhados pelo mundo. O Brasil, por ser um grande produtor agrícola mundial e consequentemente um grande consumidor desses produtos e tecnologias, foi um alvo estratégico no processo de avanço do capital internacional.

\section{Desnacionalização e internacionalização da agroindústria no Brasil}

Os anos 1990 marcaram uma mudança profunda na trajetória da economia brasileira. A crise da década de 1980 havia encerrado o longo período de crescimento econômico puxado pela industrialização, levando a mudanças na orientação da economia. Como em períodos anteriores, a crise econômica levou a mudanças institucionais, colocando em xeque o conjunto de políticas até então vigentes.

A mudança no pacto de poder, que se inicia progressivamente no governo Sarney (1986-1989), se acelera no governo Collor (1990-1992) e se aprofunda no governo FHC (1995-2002). O desenvolvimentismo, vitorioso politicamente desde os anos 1930, é paulatinamente abandonado em favor do liberalismo, na condução da economia. A partir de então, os planos econômicos priorizam o combate à inflação e a política macroeconômica de ajustes, ao invés do crescimento econômico e das 
políticas setoriais de incentivo à indústria que eram predominantes no período anterior.

O processo de afastamento do Estado brasileiro de atuação direta nos setores produtivos durante a década de 1990, no contexto de abertura e grande liquidez do capital internacional, foi o grande responsável pela desnacionalização da agroindústria e da indústria de alimentos brasileira. Os grupos brasileiros estavam estrangulados financeiramente, vindo de anos de incertezas quanto à demanda e ao crescimento interno. Após o plano Real ocorre aumento significativo do consumo de alimentos, mas que rapidamente se esgota, frustrando os investimentos realizados. O aumento de juros e o câmbio valorizado completam o quadro de dificuldades.

No âmbito externo, os grupos econômicos dos Estados Unidos lideravam um processo de investimentos internacionais, com apoio do governo Clinton (19932000). Sob seu governo, houve pressão sobre os países latino-americanos para implementação das políticas de austeridade do FMI (em virtude da crise da dívida), de abertura do mercado aos investimentos externos e as importações e de privatizações em larga escala. Os dados da UNCTAD demonstram que os investimentos externos realizados pelo conjunto dos países desenvolvidos estavam em queda nos anos imediatamente anteriores ao governo Clinton, mas iniciando então um expressivo crescimento, partindo de pouco mais de US $\$ 200$ bilhões em 1993, e chegando a mais de US $\$ 1$ trilhão em $2000^{3}$. No mesmo período, o recebimento de investimentos estrangeiros pelo conjunto de países "em desenvolvimento", passou de US $\$ 75$ bilhões para US $\$ 231,5$ bilhões, enquanto no Brasil, passou de pouco mais de US\$1 bilhão, para mais de US\$ 30 bilhões ${ }^{4}$.

Nos anos de maior entrada de investimentos estrangeiros no Brasil, as fusões e aquisições representaram a maior parte do capital, como se pode observar no gráfico 01 . Isto indica que pouco houve de investimentos reais, no sentido de criação de nova capacidade produtiva, predominando transferências de patrimônio.

3Dados de UNCTADSTAT Datacenter- Foreign Direct Investment, disponível em https://unctadstat.unctad.org/wds/ReportFolders/reportFolders.aspx?sCS ChosenLang=en

${ }^{4}$ Idem. 


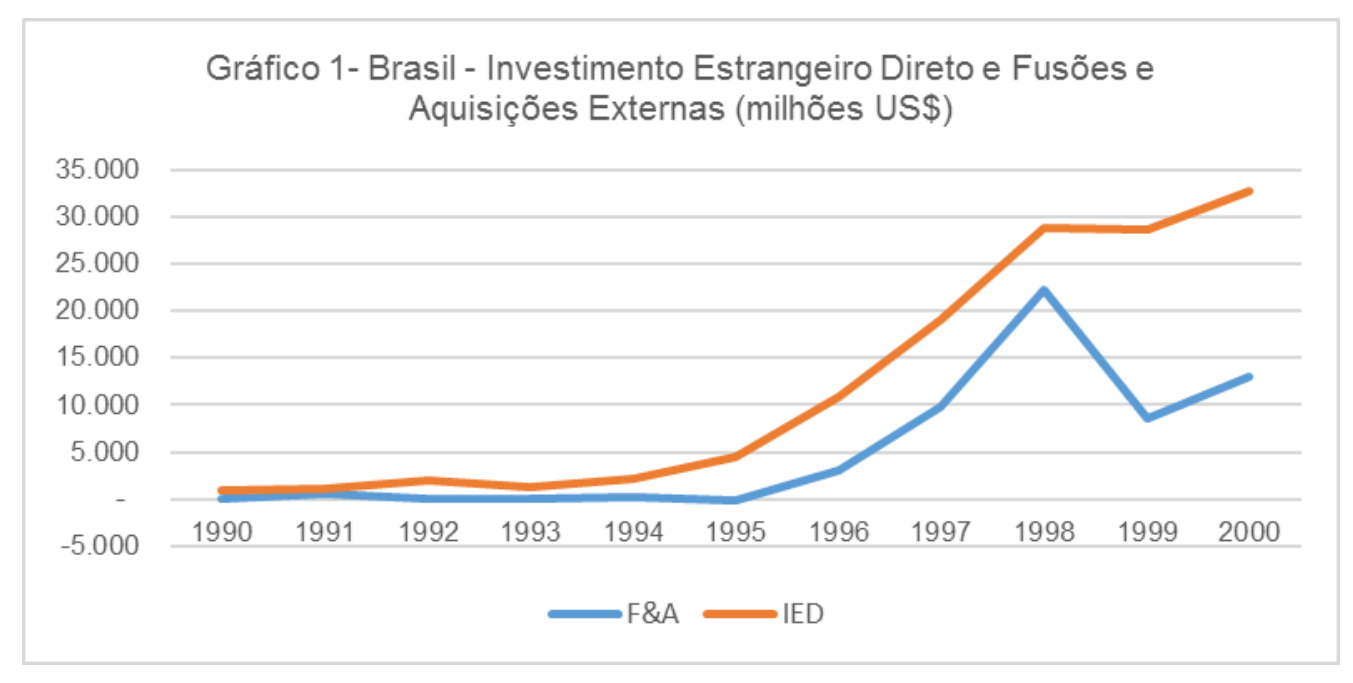

Fonte: UNCTAD. World Investment Report.

Nos anos de 1997 a 2000, nos quais houve crescimento da entrada de IED, o volume de recursos de fusões e aquisições também cresce significativamente, atingindo 52\% do IED em 1997 e $77 \%$ em 1998. Neste processo, grandes empresas e fundos de investimentos miravam especialmente as empresas estatais e grandes grupos privados dos países do terceiro mundo em crise. Os grupos internacionais, com grande alavancagem financeira, partiram para amplo processo de aquisições de empresas brasileiras dos mais variados setores.

Este fenômeno não ocorreu apenas no Brasil, pois durante toda a década de 1990, do total de investimentos estrangeiros diretos no mundo, mais da metade foi de fusões e aquisições ${ }^{5}$. O grande volume de aquisições de empresas demonstra a aceleração do processo de centralização do capital e redução da concorrência, com fortalecimento dos monopólios internacionais dos países desenvolvidos.

Os subsetores ligados à agricultura, produção de insumos agrícolas, industrialização de alimentos, frigoríficos entre outras foram alvo preferencial das aquisições. Entre os anos de 1994 e 2003 foram registrados 312 processos de

\footnotetext{
${ }^{5}$ Dados da UNCTAD citados por Santos (2012) apontam que na média da década de 1990, mais de 54\% do total do IED foi direcionado as F\&A. O autor aponta ainda que naquela década, 92,2\% do capital responsável pelas F\&A era oriundo dos países desenvolvidos.
} 
fusões e aquisições nos setores nacionais de alimentos, bebidas e fumo no Brasil (Benetti, 2004) $^{6}$.

As empresas compradas eram líderes em seus setores, com grandes estruturas de produção e comercialização, mas que passavam por problemas financeiros diante da crise nacional. A desnacionalização nada teve a ver com incapacidade tecnológica ou competitiva como muito se propagou no período, mas apenas com estratégia monopolista de entrada em novos mercados. Os grupos internacionais adquiriram empresas para eliminar concorrentes e absorver seu conhecimento produtivo e de mercados específicos. Isto foi amplamente discutido em trabalhos como Espíndola (2002), Benetti (2004), Aoun, Verdis e Sato (2008), Sampaio (2003), Correa (2004) entre outros.

Nos anos 2000, o volume geral de fusões e aquisições é inferior ao da década de 1990, mas continua ocorrendo especialmente nos setores ligados à agricultura e agroindústria. $\mathrm{O}$ gráfico 2 demonstra que $\mathrm{o}$ volume de fusões e aquisições em dólares retoma o crescimento a partir de 2010, atingindo o ápice em 2017.

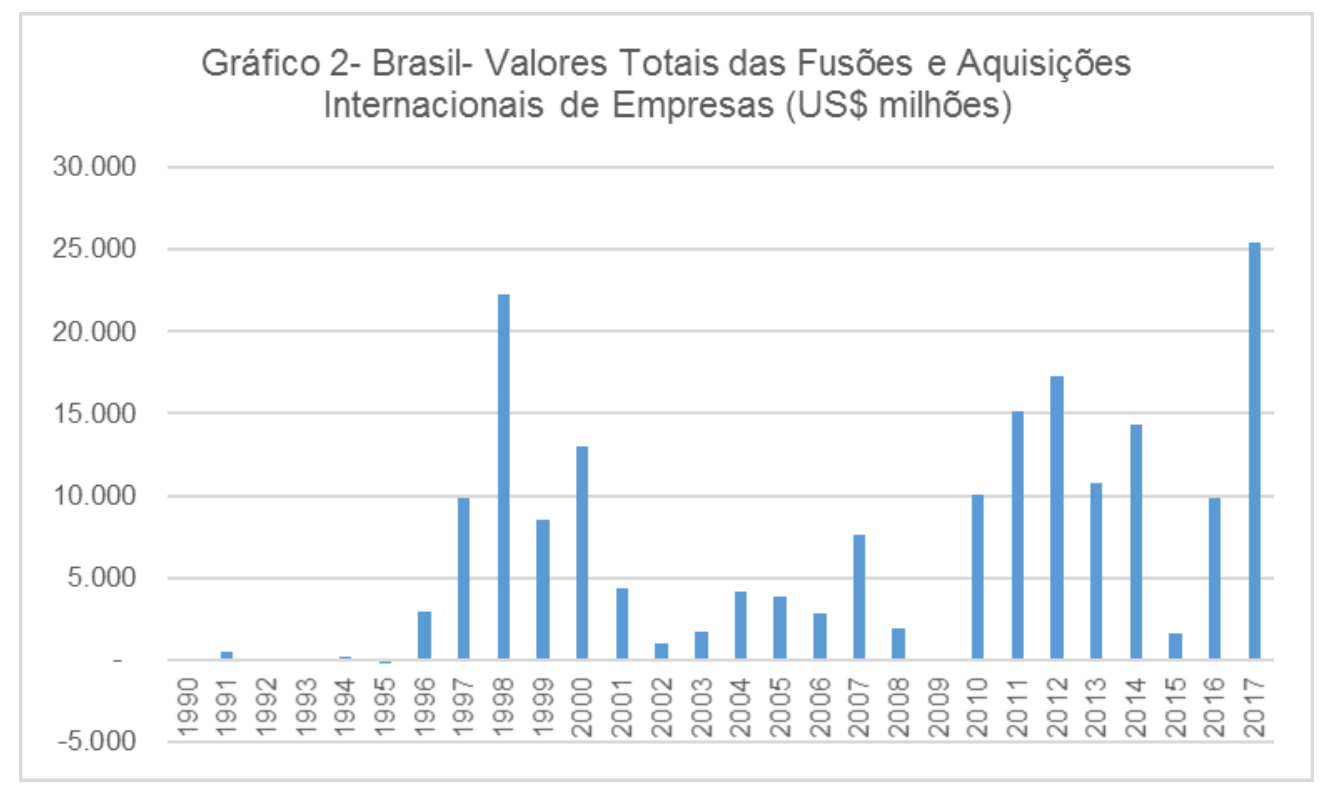

Fonte: UNCTAD. World Investment Report.

O processo de desnacionalização e centralização do capital se aprofunda mais especificamente no setor de sementes e biotecnologia. No período 1999-2013

\footnotetext{
${ }^{6}$ Os dados sistematizados por Benetti (2004) demonstram que por exemplo, entre os anos de 1991-2001, os maiores grupos estrangeiros - Parmalat, Bunge \& Born, Macri, Louis Dreyfus, ADM, Sara Lee, Danone e Milkaut, compraram ao todo 53 empresas brasileiras.
} 
os grupos Monsanto, Bayer Cropscience, Dow Agroscience e KWS adquiriram 29 empresas brasileiras (Bandeira, 2015).

É importante ressaltar que estes grupos internacionais já haviam passado por imenso processo de centralização do capital por fusões e aquisições internacionais na década de 1990 como demonstraram Assouline, Jouly e Lemarié (2001). Os autores demonstram que até os anos 1980, a produção de insumos agrícolas químicos (fertilizantes e defensivos), estavam ligados à indústria petroquímica, enquanto a produção, adaptação e pesquisa de sementes estava ligada à empresas específicas e à grandes instituições de pesquisa (em geral públicas). A partir deste período, as petroquímicas começam a vender a parte de insumos agroquímicos, e começa a ocorrer uma fusão das empresas de fabricação de defensivos e fertilizantes, com as de sementes, pesquisas e demais insumos agrícolas.

Com estas aquisições, em maioria de grupos de pesquisa e desenvolvimento em biotecnologias e adaptação de culturas às condições regionais de diferentes países, empresas como a Monsanto avançam o domínio tecnológico sem necessariamente desenvolver inovações, pois também se apropriam em grande quantidade do conhecimento das empresas adquiridas.

Nos anos 2000, durante o governo Lula, o Estado brasileiro assume parte da política monopolista, como haviam feito os países desenvolvidos na década anterior, e apoia os grandes grupos nacionais, buscando reverter 0 processo de desnacionalização e desindustrialização. Grupos nacionais da agroindústria e indústria de alimentos passaram a contar com amplos recursos, especialmente via BNDES, tanto para investimentos e reestruturação interna, quanto para aquisições de grupos estrangeiros, numa lógica inversa a da década de 1990. Internacionalização ao invés de desnacionalização.

O BNDES já havia anteriormente ampliado o apoio ao setor agropecuário quando da crise do Sistema Nacional de Crédito Rural na metade da década de 1980. No período 1986-1994 o setor agropecuário passa de 5\% dos desembolsos totais do BNDES para $25 \%$ conforme dados de Faveret Filho e Paula (2002). Esta era a atuação tradicional do BNDES antes da década de 1990, quando foi reduzido a órgão de gerenciamento das privatizações por FHC. Nos anos seguintes torna a cair chegando a 10\% em 1998 (Faveret Filho e Paula, 2002). 
Nos anos 2000 o BNDES ampliou de forma intensa o apoio financeiro aos setores produtivos de duas grandes maneiras. Por um lado criou inúmeros novos programas e linhas, expandiu recursos disponíveis e reduziu taxas de juros. Por outro lado, o BNDES ampliou o apoio via compra de ações (chamada de renda variável) das grandes empresas com potencial de internacionalização.

$O$ aporte de recursos do BNDES foi crescente para a agropecuária e agroindústria nos anos 2000. Após a crise internacional de 2008 o BNDES ampliou programas visando manter os níveis de investimento dos setores produtivos. No tocante ao agronegócio, as fontes internacionais de crédito, até então abundantemente utilizadas pelos grandes produtores reduziram recursos. As tradings que desde os anos 1990 financiaram as vendas antecipadas de safras direcionaram recursos para suas matrizes.

O BNDES cria então o Programa de Crédito Especial Rural (Procer), o Programa de Sustentação do Investimento (PSI), os quais liberaram no período 2009-2011, $R \$ 16,3$ bilhões para as empresas da agroindústria (BNDES, 2012). Assim, o BNDES passou novamente a atuar tanto como um braço regular da política industrial do Estado, quanto agente na política anticíclica no período de crise.

A grande mudança na estratégia do BNDES, em direção a dinâmica financeira foi a de reduzir os apoios via financiamento aos grandes grupos e ampliar a participação acionária nestes (Oliveira, 2015). Esta constituiu a política chamada de Campeões Nacionais. O BNDESpar ampliou suas operações nos anos 2000 (especialmente após a crise internacional de 2008), tornando-se inclusive a atividade mais rentável do BNDES, como apontaram Musachio e Lazzarini (2015). Segundo dados de BNDES (2011), os desembolsos do BNDES para internacionalização de empresas totalizaram $\mathrm{R} \$ 14$ bilhões em 5 anos.

O apoio do BNDES a operações de aquisições e expansão internacional dos grupos JBS e Marfrig, por exemplo, se deu primordialmente na forma de participação acionária nas operações. Os dados de Oliveira (2015) demonstram que os grupos agroindustriais receberam $R \$ 9,5$ bilhões do total de 10,4 bilhões de investimentos em renda variável aplicados pelo BNDES de 2006 a 2011. Apenas os grupos JBS e Marfrig receberam juntos $70 \%$ deste total (Oliveira, 2015).

No entanto, o fortalecimento de determinados grupos nacionais não significou que as tendências anteriores tenham sido revertidas. O papel dos mercados 
internacionais nos preços e na dinâmica da produção interna, bem como o papel de grandes grupos internacionais aqui instalados se ampliou. A ação dos grandes grupos internacionais no Brasil se ampliou, inclusive com a continuidade das aquisições em grande escala de grupos nacionais dos setores do agronegócio (Açúcar e álcool, biotecnologia, madeira, papel e celulose, insumos agrícolas, laticínios entre muitos outros), como apontaram Corrêa (2012), Oliveira (2016), Galvão (2014), Mazzochin (2016), Souza (2014), Camilo (2018) entre outros.

A centralização do capital na última década acentuou-se sobretudo na pesquisa tecnológica de insumos. As inovações tecnológicas, que se tornaram centrais, especialmente as biotecnológicas concentram-se nas mãos dos mesmos grupos agroindustriais-financeiros-comerciais como Monsanto, Syngenta e Novartis, que além de comprarem as empresas brasileiras de pesquisa em biotecnologia, indiretamente controlam a pesquisa pública. Os grandes grupos fazem contratos nos quais financiam a pesquisa na Embrapa, mas apropriam-se dos royalties na comercialização. Assim, inclusive em relação à inovação tecnológica, a questão financeira é central.

\section{Desnacionalização no setor de sementes e genética vegetal}

O setor de sementes e genética vegetal sofreu grandes transformações durante o processo de desnacionalização e internacionalização, vivido no final do século passado - retratado e debatido anteriormente - sendo um dos setores que mais sofreram os efeitos desta dinâmica, haja vista a magnitude da desnacionalização e da concentração no mesmo. Apenas nas culturas de soja e milho, que juntas representam $74 \%$ do setor ${ }^{7}$, fica evidente o domínio de três grupos no escalão tecnológico de ponta, com uma tríade, dois lados num bloco europeuamericano (Bayer-Monsanto, e Dow-Du Pont) e outro chinês (ChemChina, com as aquisições da Nidera e Syngenta).

Há três processos principais para o entendimento do ocorrido no setor: primeiro, os investimentos se dirigiram para os países da periferia do sistema que estavam a passar por um processo de ajustamento para os interesses das

\footnotetext{
${ }^{7}$ ABRATES. Disponível em: https://www.abrates.org.br/noticia/mercado-de-sementes-movimenta-r10-bi-ao-ano-no-brasil. Acesso em fevereiro de 2019.
} 
transnacionais na divisão internacional do trabalho, na busca do capital por novos territórios - como era o caso do Brasil - para a acumulação financeira. Segundo, pela capacidade de drenar renda com a forte financeirização da economia, na agricultura, sobretudo após a Rodada Uruguai (1986-94) da OMC, com uma dinâmica de acumulação flexível. Terceiro, pelo surgimento da inovação biotecnológica, dentro da engenharia genética, com pesquisas de custos muito elevados, fazendo com que poucas empresas pudessem permanecer na concorrência. Estes fatores foram fundamentais para o atual cenário de oligopolização e desnacionalização no setor de sementes de milho e soja, principais culturas do agro brasileiro.

No fim do século $X X$ o Brasil rompe com o modelo de substituição de importações, conforme expresso por Kupfer (2005), limitando ou até mesmo abandonando este modelo que foi a base da industrialização nacional desde a Revolução de 1930 como salientado em Mamigonian (2000), priorizando a abertura de mercado, especialmente para a movimentação de capital. Este processo, característico das periferias do capitalismo, levou a uma crescente desnacionalização da indústria de fornecimento de insumos na agricultura brasileira como exposto por Espíndola (2002), Benetti (2004), Sampaio (2003), Correa (2004) entre outros.

No setor de sementes não foi diferente, com a particularidade que boa parte da tecnologia no desenvolvimento de novas cultivares continuou sendo pública. Porém como mostrado em Gonçalves (2012) a financeirização que provocou uma mudança no padrão de financiamento do custeio da safra via venda antecipada lastreada em títulos financeiros emitidos pelo setor privado, somada às limitações impostas na extensão rural pública, fizeram com que as instituições estatais de pesquisa se tornassem dependentes das corporações estrangeiras que compraram as empresas de sementes do Brasil, responsáveis pela difusão da tecnologia ao produtor.

As aquisições neste setor se deram de forma muito incisiva no início dos anos 2000, num cenário onde as multinacionais faziam as aquisições das empresas no Brasil, não entrando necessariamente com suas marcas para a comercialização dos produtos. Isso se devia sobretudo pela necessidade de adquirir a estrutura e a experiência que as empresas brasileiras já tinham na extensão rural, com marcas conhecidas e principalmente, com o conhecimento das condições naturais, pois as 
sementes precisavam estar adaptadas ao clima, solo, altitudes e experimentadas em diferentes locais e épocas do ano. Todo esse trabalho já havia sido desenvolvido pelos institutos públicos de pesquisa, mas a financeirização abria uma nova dinâmica como exposto em Gonçalves (2012) e isso interessava muito às corporações. As mudanças provocadas na OMC e a postura que o Brasil adotou ao aceitar os termos da Rodada Uruguai colocaram a comercialização de sementes como um atrativo, sobretudo com a possibilidade da comercialização da transgenia.

A Rodada Uruguai da OMC ficou conhecida como o maior acordo comercial já feito, por instituir um marco jurídico-institucional para o comércio exterior de produtos agrícolas. Mas o grande impacto se deu pelos termos do Acordo sobre Aspectos dos Direitos de Propriedade Intelectual Relacionados ao Comércio, conhecido pela sigla do inglês TRIPS ${ }^{8}$. O Brasil foi um dos países que ratificaram tais acordos praticamente em plenitude e, pelas características de ser uma economia com uma agricultura pujante, foi diretamente impactado pelo acordo.

Segundo Lampreia (1995) o Acordo sobre TRIPS divide-se em três partes, a primeira contendo disposições gerais e princípios básicos, tais como tratamento nacional e uma cláusula de nação mais favorecida; a segunda discorrendo sobre cada um dos direitos em sucessão (copyright, marcas, apelações geográficas, desenhos industriais, patentes etc.); e a terceira indicando as obrigações dos membros no sentido de estabelecer procedimentos no contexto de suas legislações nacionais para assegurar que os direitos sejam efetivamente protegidos e respeitados. Esta terceira parte o Brasil cumpriu com a Lei de Cultivares (1997) que possibilitou a cobrança de royalties e o patenteamento de cultivares em território nacional.

O que se viu na sequência foi uma verdadeira ofensiva das corporações que viriam a ser os oligopólios do setor. Boa parte delas, com origem no setor químico e farmacêutico, como o caso da Monsanto, que conforme Guerrante (2002) de empresa farmacêutica se converteu em corporação química e depois veio a ser a líder isolada no segmento de biotecnologias. Este interesse das empresas químicas e farmacêuticas pelo setor de sementes foi evidenciado por Mooney (1987), que já na época salientava o posicionamento estratégico que as sementes poderiam ter

\footnotetext{
${ }^{8}$ Em inglês: Agreement on Trade-Related Aspects of Intellectual Property Rights.
} 
para o setor de insumos na agricultura, sobretudo com complexidades da nova financeirização que ocorria, possibilitando a acumulação financeira a partir do setor.

O quadro 01 mostra de um modo geral o amplo processo de concentração e internacionalização no setor, com as empresas representadas dominando quase a totalidade da comercialização de sementes de milho e soja no Brasil.

Quadro 01: Aquisições das principais corporações no setor de sementes

\begin{tabular}{|c|c|c|}
\hline CONGLOMERADO & AQUISIÇÕES & ANO DA OPERAÇÃO \\
\hline \multirow{12}{*}{ Monsanto } & Braskalb & 1999 \\
\hline & Grupo Maeda & $s / d$ \\
\hline & Seminis & 2005 \\
\hline & Agroeste & 2007 \\
\hline & Agroceres & 1997 \\
\hline & FT Sementes* & 1996 \\
\hline & $\begin{array}{l}\text { Cargill do Brasil (divisão de } \\
\text { sementes) }\end{array}$ & 2000 \\
\hline & MDM & 2008 \\
\hline & Alellys & 2008 \\
\hline & CanaVialis & 2008 \\
\hline & D\&P Land & 2007 \\
\hline & Nidera do Brasil & 2016 \\
\hline \multirow{5}{*}{ Bayer CropScience } & Granjas 4 Irmãos & 1998 \\
\hline & Mitla Pesquisa Agrícola & 1999 \\
\hline & Wehrtec & 2012 \\
\hline & Sementes Fartura & 1999 \\
\hline & Sementes Ribeiral & 1999 \\
\hline
\end{tabular}


BANDEIRA, MEDEIROS

\begin{tabular}{|c|c|c|}
\hline & Soy Tech Seeds & 2011 \\
\hline & Melhoramento Agropastoril & 2012 \\
\hline & Agrodul Genética & 2013 \\
\hline \multirow{8}{*}{ Dow AgroSciences } & $\begin{array}{lll}\text { Empresa } & \text { Brasileira } & \text { de } \\
\text { Sementes } & & \end{array}$ & 2000 \\
\hline & Agromen & 2007 \\
\hline & Sedol & $\mathrm{s} / \mathrm{d}$ \\
\hline & Híbridos Colorado & 1998 \\
\hline & UBS da Coodetec & 2008 \\
\hline & Dinamilho & 1998 \\
\hline & FT Biogenética* & 1998 \\
\hline & Coodetec & 2015 \\
\hline \multirow{3}{*}{ KWS } & Delta Pesquisa e Sementes & 2012 \\
\hline & Riber Sementes & 2012 \\
\hline & $\begin{array}{l}\text { Semília Genética e } \\
\text { Melhoramento }\end{array}$ & 2012 \\
\hline \multirow[t]{2}{*}{ ChemChina } & Syngenta & 2017 \\
\hline & Nidera & 2018 \\
\hline
\end{tabular}

Fonte: Bandeira (2015), com atualizações.

O processo de concentração de empresas e desnacionalização mostrado no quadro anterior, se refletiu na mudança que passou a existir dentro do setor, com base numa divisão entre as cultivares e a biotecnologia. O mercado de cultivares era o preponderante até o início dos anos 2000, mas passou por mudanças e se transformou em coadjuvante com o advento das tecnologias transgênicas. Ou seja, 
as cultivares continuaram existindo, porém a mutação gênica, que possibilita uma resistência a estiagem, a lagartas ou diversas patologias, se converte no principal fator ${ }^{9}$. Em grande medida isso ocorreu pelo processo de financeirização, haja vista que a cobrança de royalties se torna muito mais lucrativa que a comercialização de cultivares convencionais. Isso marcou uma nova dinâmica tecnológica, em que não eram todas as empresas que poderiam participar, assim as que não tinham condições financeiras, foram compradas como ilustrado no quadro 01. Este novo paradigma tecnológico no setor marcou uma nova etapa como exposto em Vieira Filho \& Silveira (2013), Carvalho (2003), Villas Bôas (2008), Fuck (2009), Santos (2013), Aviani (2014) entre outros.

A tecnologia transgênica se disseminou pelo território brasileiro, chegando aos níveis elencados no gráfico 03.

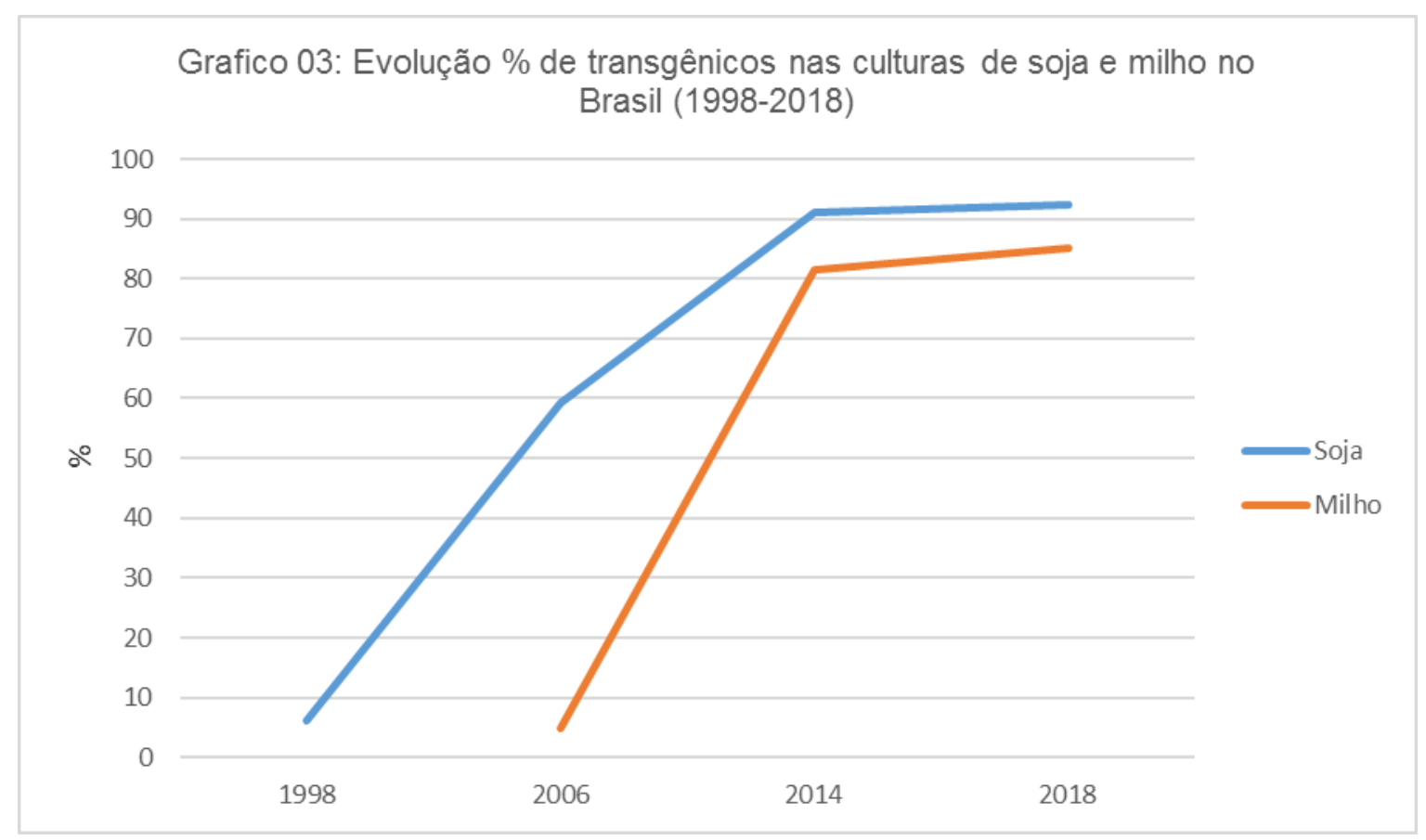

Fonte: ABRATES.

${ }^{9}$ Cultivar é uma forma de planta que passou por mudança em um fenótipo ou genótipo selecionado, alterando alguma característica desejada na planta. A transgenia é uma mudança no DNA criando um novo organismo, este novo organismo passa a ser um produto de inovação e a sua utilização passa a ser cobrada na forma de royalties. 
Esse domínio dos transgênicos também explica a ineficiência em reverter o processo de desnacionalização e desindustrialização, em parte revertido em outros setores a partir de aporte do BNDES, como mostrado no início deste trabalho. O fato de haver um sistema de royalties diretamente ligado ao setor produtivo, fez com que não houvesse mudanças nos gestores da inovação e fornecimento de tecnologia para os produtores brasileiros. O papel dos grupos estrangeiros se manteve com protagonismo na produção interna, mantendo o domínio no setor. Como fator novo, ocorreu a inserção de investimentos chineses comprando a Syngenta e a Nidera. A primeira uma gigante no setor, de origem suíça tinha relevância nos negócios no Brasil e no mundo, tanto na biotecnologia quanto na química, a segunda, com forte participação nos mercados de semente do Brasil e da Argentina, que estão entre os maiores do mundo.

Atualmente o mercado de sementes no Brasil é o segundo maior do mundo, atrás apenas do dos Estados Unidos. Conforme dados do Registro Nacional de Cultivares (RNC), do Ministério da Agricultura, $75 \%$ do total é de empresas privadas, maioria multinacionais, $24 \%$ parceria público privadas e apenas $1 \%$ são de empresas públicas. ${ }^{10}$

Chama a atenção também os valores pagos pelos royalties no Brasil quando comparados com os vizinhos da América do Sul. Enquanto Argentina paga 16 dólares por hectare e o Paraguai 25, o Brasil paga 40. ${ }^{11}$ Isso se deve em grande medida pelo Brasil ter adotado na sua integralidade os termos da Rodada do Uruguai da OMC.

A partir dos anos 2000 houve uma evolução nas disputas comerciais entre o ocidente e a iniciativa chinesa. A China apresentou um forte crescimento econômico, em grande medida pelas estratégias do socialismo de mercado chinês na atual fase do capitalismo. Como mostrado, o setor genético na agricultura se converteu em um

\footnotetext{
10 Dados presentem em: https://www.abrates.org.br/noticia/mercado-de-sementes-movimenta-r-10-biao-ano-no-brasil. Acesso em fevereiro de 2019. Também presentes em: http://sistemas.agricultura.gov.br/snpc/cultivarweb/cultivares_registradas.php. Acesso em fevereiro de 2018.

11 Disponível em:

https://webcache.googleusercontent.com/search?q=cache:ZgK1uNz6UzQJ:https://canalrural.uol.com. $\mathrm{br} /$ noticias/sojicultor-brasileiro-paga-ate-150-mais-por-royalties-intacta-que-seus-vizinhos-

$68385 /+\& c d=4 \& h l=p t-B R \& c t=c l n k \& g l=b r$. Acesso em fevereiro de 2019.
} 
equipamento do sistema financeiro e passou a ser estratégico frente a financeirização acelerada da economia. A estatal chinesa ChemChina atualmente faz frente ao oligopólio que dominou o mundo da genética vegetal na década passada. A International Seed Federation estima que as aquisições da mesma, somada ao mercado de sementes chinês que é estatal e dominado por ela, representa cerca de $25 \%$ do mercado mundial, sendo que praticamente todo o resto está dominado pelo conglomerado Monsanto- Bayer e Dow - Du Pont.

\section{Considerações finais}

No caso brasileiro o aprofundamento da dinâmica retratada no trabalho foi marcada pelo corte de programas de financiamento públicos na década de 1990, pela expansão dos financiamentos diretos via tradings, pela desnacionalização do setor agroindustrial via aquisições, pela ampliação do papel financeiro dos grandes grupos internacionais na produção brasileira e pela redução do peso da propriedade da terra como elemento determinante até mesmo para os grandes produtores empresariais, pela concentração da produção e pela imensa expropriação de médios e pequenos produtores

A década de 1990 marcou uma virada profunda na economia brasileira que culminou com a ampliação da influência do capital monopolista internacional na economia nacional. Combinaram-se os efeitos da crise econômica geral com a crise do crédito estatal, a abertura econômica e a agressiva entrada de grandes grupos estrangeiros no setor agropecuário-agroindustrial. Isto resultou em forte crise agrícola, ociosidade de recursos, abandono da produção (especialmente por produtores menos capitalizados), renegociação das dívidas e um novo sistema de financiamento privado baseado nas compras antecipadas de safras pelas tradings internacionais e nas bolsas de mercadorias com a criação de títulos do agronegócio.

Nos anos 2000 novas mudanças ocorrem, especialmente o novo crescimento do papel do Estado brasileiro no financiamento: criação de programas de recuperação e investimento para as cooperativas agropecuárias; programas de financiamento para a agricultura familiar e a aquisição de alimentos; ampliação da participação do BNDES no financiamento agropecuário; explosão das exportações agropecuárias e alta dos preços internacionais; fortalecimento do agronegócio no 
pacto de poder e nas instituições de financiamento, estabelecimento de dois planos safra: o da agricultura familiar e da agricultura patronal; a imensa centralização de capital em grandes grupos internacionais no setor de insumos agrícolas e biotecnologia e de grupos nacionais na agroindústria.

O panorama se tornou mais complexo, com a internacionalização dos grandes grupos brasileiros e o aumento do papel do Estado brasileiro na questão financeira, ao lado do crescimento da ação dos grandes grupos internacionais. A explosão nas exportações de grãos nos anos 2000, somada a ampla internacionalização fizeram com que o setor de sementes passasse a ter protagonismo maior que anteriormente, servindo de ponta de lança para a drenagem de renda no território nacional.

A forma com que o Brasil se integrou às novas regras da Organização Mundial do Comércio, somadas a um cenário de grande liquidez no mercado internacional e abertura da economia nacional, fizeram com que o País se comprometesse na divisão internacional do trabalho. A modernização do território e a constante introdução de tecnologias, foi a porta de entrada para o comércio de tecnologias dentro do mercado de cultivares. As taxas tecnológicas e royalties, embora benéficas para o sistema produtivo, possibilitando uma produção com mais eficiência, se tornaram também mecanismos de drenagem de renda para 0 capitalismo financeiro internacional.

Ao compararmos os valores pagos no Brasil com seus vizinhos do Mercosul, podemos ter uma dimensão de como a legislação brasileira adaptada às TRIPS fez com que a agricultura do País ficasse submissa. Uma realidade manifestada na agricultura moderna e financeirizada do Brasil que é reflexo do processo de desindustrialização e posicionamento crítico na divisão internacional do trabalho.

Fatores estes que estão atrelados ao ocorrido na abertura econômica e desnacionalização que não foi revertida por completo com as políticas de Estado realizadas no Governo Lula. No setor de genética vegetal os impactos destas políticas foi menor, sem conseguir portanto, fazer o resgate que ocorreu em outros setores. Apenas uma valorização das Instituições Públicas de pesquisa e a valorização do seu papel no desenvolvimento dos serviços e tecnologias poderá deixar a produção nacional menos refém dos interesses corporativos internacionais. 


\section{REFERÊNCIAS}

AOUN, S.; VERDIS, A. R.; SATO, G. S. Dinâmica das fusões e aquisições no investimento direto estrangeiro: especificidades da indústria de alimentos e bebidas no Brasil, 1996-2006. Informações Econômicas, São Paulo, v. 38, n.3, p. 67-76, mar, 2008.

ASSOULINE, Gérald, JOLY, Pierre-Benoit, LEMARIÉ, Stephanie. Biotecnologias vegetais e reestruturações do setor de provisões agrícolas: um horizonte estratégico marcado por fortes incertezas. In: Ensaios FEE, Porto Alegre, v.22, n. 02, 2001.

AVIANI, D. M. Melhoramento vegetal como fator de competitividade internacional. ANPAD. In: XXXVII Encontro ANPAD, Rio de Janeiro, 2013.

BALESTRO, Moisés V. LOURENÇO, Luiz C. B. Notas para uma análise da financeirização do agronegócio Além da volatilidade dos preços das commodities. In: BUAINAIN, Antônio M. ALVES, Eliseu et all (org.). O mundo rural no Brasil do século 21: a formação de um novo padrão agrário e agrícola. Brasília, DF: Embrapa, 2014.

BANDEIRA, João L. A geografia econômica das sementes: dos grandes monopólios ao sudoeste do paraná. Francisco Beltrão: UNIOESTE, 2015. Dissertação de Mestrado em Geografia.

BEL FILHO, Egmar, LIMA, Jaldir Freire et al. Apoio do BNDES à agroindústria: retrospectiva e visão de futuro. In: BNDES. BNDES 60 anos: perspectivas setoriais. Volume II. Brasília: BNDES, 2012.

BENETTI, Maria Domingues. Globalização e Desnacionalização do Agronegócio Brasileiro no Pós-1990. Documentos FEE, n 61. Porto Alegre: FEE, 2004.

BNDES. BNDES 60 anos: perspectivas setoriais. Volume II. Brasília: BNDES, 2012. BNDES. Informe Setorial n. 20. Abril, 2011.

CAMILO, Pablo J. A dinâmica geoeconômica da comercialização, logística e transporte da cadeia produtiva do leite na Região Sul do Brasil. Florianópolis: UFSC, 2018 (Tese de Doutorado em Geografia).

CARVALHO, S.M. P. Propriedade Intelectual na Agricultura. Tese (Doutorado em Política Científica e Tecnológica). Departamento de Política Científica e Tecnológica, Instituto de Geociências, Unicamp, Campinas, 2003.

CENTRE FOR RESEARCH ON MULTINATIONAL CORPORATIONS. Financing Food, Financialisation and Financial Actors in Agriculture Commodity Markets. SOMO paper. Amsterdã: SOMO, April 2010.

CHANG, Ha-Joon. Chutando a escada: a estratégia do desenvolvimento em perspectiva histórica. São Paulo: Unesp, 2004.

CORREA, Domingos S. Fusões e aquisições nos segmentos carne bovina, óleo de soja e sucroalcooleiro. São Paulo: FFLCH/USP, 2012. (Tese de Doutorado em Geografia).

CORREA, Domingos S. O movimento de fusões e aquisições de empresas e o processo de privatização e desnacionalização na década de 1990: O caso brasileiro. São Paulo:

FFLCH/USP, 2004. (Dissertação de Mestrado em Geografia). 
ESPÍNDOLA, Carlos J. As Agroindústrias de Carne do Sul do Brasil. (Tese de Doutorado em Geografia). São Paulo: FFLCH/USP, 2002.

FAVERET FILHO, Paulo, PAULA, Sérgio de. A Agroindústria. In BNDES. BNDES 50 anos: histórias setoriais. Brasília: BNDES, 2002.

FUCK, M. P. A coevolução tecnológica e institucional na organização da pesquisa agrícola no Brasil e na Argentina. 2009. Tese (Doutorado em Política Científica e Tecnológica). Departamento de Política Científica e Tecnológica, Instituto de Geociências, Unicamp, Campinas, 2009.

GALVÃO, Anderson. A nova etapa do desenvolvimento agrário e o papel dos agentes privados na inovação agropecuária. In: BUAINAIN, Antônio M. ALVES, Eliseu et all (org.). O mundo rural no Brasil do século 21: a formação de um novo padrão agrário e agrícola.

Brasília, DF: Embrapa, 2014.

GONÇALVES, José Sidnei. Do Bonde ao Trem-bala: o fim do domínio da genética pública e o novo padrão de financiamento do custeio agropecuário. Análise e Indicadores do Agronegócio, v. 7, n. 4, abril 2012.

GUERRANTE, R. S. Transgênicos: uma visão estratégica. Rio de Janeiro: EQ/UFRJ, 2002 (Dissertação de Mestrado).

CAMILO, Pablo J. A dinâmica geoeconômica da comercialização, logística e transporte da cadeia produtiva do leite na Região Sul do Brasil. Florianópolis: UFSC, 2018 (Tese de Doutorado em Geografia).

HOWARD, Philip P. Visualizing Consolidation in the Global Seed Industry: 1996-2008. In: Sustainability 2009, 1, 1266-1287; doi:10.3390/su1041266.

LAMPREIA, Luís Felipe. Resultados da Rodada Uruguai: uma tentativa de síntese. Estud. av. vol.9 no.23 São Paulo Jan./Apr. 1995.

LENIN, Vladimir llitch. Imperialismo: Fase Superior do Capitalismo. Campinas: Unicamp, 2011.

KUPFER, David. A indústria brasileira após a abertura. In: CASTRO, A; LICHA, A; PINTO JR, H; SABOIA, J. Brasil em desenvolvimento, V. 01. Rio de Janeiro: Civilização brasileira, 2005.

MAMIGONIAN, Armen. Teorias sobre a Industrialização Brasileira. Cadernos Geográficos, n. 2, maio 2000.

MAZZOCHIN, Marinez S. A Dinâmica Geoeconômica do Setor Florestal Brasileiro: da Gênese à Reestruturação. Florianópolis: UFSC, 2016. (Tese de Doutorado em Geografia).

MEDEIROS, Marlon C. A geografia do mercado mundial de produtos agroalimentares e 0 papel do Brasil. In: Revista Ra'e ga: o espaço geográfico em análise. v.31, p.260 - 279, 2014.

MEDEIROS, Marlon, C. Capital financeiro e o mercado mundial de produtos agrícolas. In: Brasil: Temas de Geografia Econômica. Rio Grande: Ed. Da FURG, 2015.

MUSACCHIO, Aldo, LAZZARINI, Sérgio. Reinventando o Capitalismo de Estado. O Leviatã nos Negócios: Brasil e outros países. São Paulo: Portfolio Penguin, 2014. 
OLIVEIRA, Alessandro F. T. A internacionalização das empresas brasileiras: o Bndes e o incentivo aos grupos JBS e Marfrig. Francisco Beltrão: UNIOESTE, 2015. Dissertação de Mestrado em Geografia.

OLIVEIRA, Ariovaldo U. A Mundialização da agricultura brasileira. São Paulo: lãnde, 2016. RANGEL, Ignácio. Obras Reunidas. Vol 1 e 2. Rio de Janeiro: Contraponto/BNDES, 2005.

SAMPAIO, Fernando dos Santos. Made in Brazil: Dinâmica sócio-espacial da indústria citrícola paulista. São Paulo: FFLCH/USP, 2003. (Tese de Doutorado em Geografia Humana).

SANTOS, Leandro B. Estado, industrialização e o espaço da acumulação das multilatinas. Presidente Prudente: UNESP/FCT, 2012 (Tese de Doutorado em Geografia).

SANTOS, P.E.C. Marcos regulatórios, inovações biotecnológicas e a concentração da indústria de sementes de soja, milho e algodão no Brasil. Tese (Doutorado em Agronomia). Universidade de Brasília, Faculdade de Agronomia e Medicina Veterinária, Brasília, 2013.

SAUVIAT, Catherine. Os Fundos de Pensão e os Fundos Mútuos: Principais atores da finança mundializada. In: CHESNAIS, François. A Finança Mundializada. São Paulo: Boitempo, 2005.

SOUZA, Joel J. O complexo agroindustrial de laticínios no Brasil: o caso da região Sul. Florianópolis: UFSC, 2014 (Tese de Doutorado em Geografia).

SUZIGAN, Wilson. Estado e industrialização no Brasil. In. ODÁLIA, Nilo (Org.). O desenvolvimento ameaçado: perspectivas e soluções. São Paulo: UNESP, 1989.

VIEIRA FILHO, J. E. R.; SILVEIRA, J. M. F. J. Mudança tecnológica na agricultura: uma revisão crítica da literatura e o papel das economias de aprendizado. Rev. Econ. Sociol. Rural, Brasília, v. 50, n. 4, p. 721-742, Dec. 2012.

VILLAS BÔAS, H. D. C. A empresa pública de pesquisa e os marcos legais na indústria de sementes. Tese (Doutorado). Programa de Pós-Graduação em Ciência e Tecnologia de Sementes, Faculdade de Agronomia Eliseu Maciel, UFPEL, Pelotas, 2008.

\section{NOTAS DE AUTOR}

\section{CONTRIBUIÇÃO DE AUTORIA}

João Luciano Bandeira -Concepção. Coleta de dados, Análise de dados, Elaboração do manuscrito, revisão e aprovação da versão final do trabalho

Marlon Clóvis Medeiros - Elaboração do manuscrito. Coleta de dados Participação ativa da discussão dos resultados; Revisão e aprovação da versão final do trabalho.

\section{FINANCIAMENTO}

Não se aplica.

\section{CONSENTIMENTO DE USO DE IMAGEM}

Não se aplica.

APROVAÇÃO DE COMITÊ DE ÉTICA EM PESQUISA 
Não se aplica.

\section{CONFLITO DE INTERESSES}

Não se aplica.

\section{LICENÇA DE USO}

Este artigo está licenciado sob a Licença Creative Commons CC-BY. Com essa licença você pode compartilhar, adaptar, criar para qualquer fim, desde que atribua a autoria da obra.

\section{HISTÓRICO}

Recebido em: 01-02-2019

Aprovado em: 10-03-2019 